Article

\title{
Entanglements of Difference as Community Togetherness: Faith, Art and Feminism
}

\author{
Anna Hickey-Moody * and Marissa Willcox \\ Digital Ethnography Research Centre, School of Media and Communication, RMIT University, \\ Melbourne VIC 3001, Australia; marissa.willcox@rmit.edu.au \\ * Correspondence: anna.hickey-moody@rmit.edu.au
}

Received: 14 May 2019; Accepted: 12 September 2019; Published: 18 September 2019

check for updates

\begin{abstract}
Using a feminist, new materialist frame to activate ethico-political research exploring religion and gender at a community level both on Instagram and in arts workshops, we show how sharing ethnic backgrounds, religious beliefs, gender identities and sexualities through art practice entangles a diffraction of differences as 'togetherness'. Such entanglement creates cross-cultural interfaith understandings and gender diverse acceptance and inclusion online. We use diffraction, intra-action and entanglement as a way of framing our understanding of this 'togetherness' and show that human feelings rely on more-than-human assemblages; they rely on homelands, countries, wars, places of worship, orientations, attractions, aesthetics, art and objects of attachment. The feelings of 'community' and 'belonging' that we discuss are therefore direct products of human and non-human interactions, which we explore through arts-based research. In this article, we apply Karen Barad's feminist new materialist theories of 'diffraction', 'intra-action' and 'entanglement' to ways of thinking about human experience as intra-acting with aspects of the world that we classify as non-human. We use these new materialist frames to reconceptualize the human feelings of 'community', 'belonging' and 'what really matters' in feminist and intra-religious collaborative art practices and Instagram-based art communities. To better understand and encourage communities of difference, we argue that the feelings of 'community' and 'belonging', which are central to human subjectivity and experience, are produced by more-than-human assemblages and are central to identity. The methodologies we present are community focused, intra-active, arts-based research strategies for interrogating and understanding expressions of 'community' and 'belonging'. We identify how creative methods are a significant and useful way of knowing about communities and argue that they are important because they are grounded in being with communities, showing that the specificity of their materiality needs to be considered.
\end{abstract}

Keywords: diffraction; intra-action; entanglement; community; togetherness; faith; art; feminism; religion; belonging; methods

We are all humans, but some of us are just more mortal than others. (Braidotti 2013, p. 3)

Diffraction as a way of thinking draws attention to the agency of the non-human, the ways that the materials used to make art can change thinking and can change relationships between people ... building more than human relationships. Arts based practices offer an ideal way not only of accessing but also of reorganizing emotional investments. (Hickey-Moody 2018, p. 8)

\section{Introduction}

The feelings of 'community' and 'belonging' are products of human and non-human intra-action and enmeshment, which we explore through arts-based research. We apply the feminist new materialist concepts of 'diffraction', 'intra-action' and 'entanglement' (Barad 2007) to ways of thinking about 
human experience as intra-acting with aspects of the world that we classify as non-human. We use these new materialist frames to reconceptualize the human feelings of 'community', 'belonging' and 'what really matters' in feminist and intra-religious collaborative art practices and Instagram-based art communities. To better understand and encourage communities of difference, we argue that these feelings of 'community' and 'belonging' are produced by more-than-human assemblages and are central to identity. The methodologies we present are community-focused, intra-active, arts-based research strategies for interrogating and understanding expressions of 'community' and 'belonging'. We identify how live and creative methods are more than a way of knowing about communities, they are a way of being entangled with communities. As such, the specificity of their materiality needs to be considered.

According to Deleuze and Guattari "flesh is only the thermometer of a becoming" (Deleuze and Guattari 1994, p. 179), if we take this as an accurate description, which we do, then emotion is the psychological register of change and attachment. We have two similar strategies for mapping such becomings, and these articulate in different empirical projects. First, our (Hickey-Moody 2017, 2018, 2019; Hickey-Moody and Harrison 2018) methodology for working with faith communities ${ }^{1}$ establishes new materialist approaches to qualitative visual research methods. This project fosters interfaith relationships in childhood and is designed to help communicate the ways in which communities experience belonging and togetherness through their celebration of religious differences and various cultural practices. Second, our method for working with feminist and queer Instagram artists builds on Dolphijn and van der Tuin's (2012) new materialist approach to interviewing and Les Back's (2012) 'live' sociology or live methods, to employ a method of "Instagram live interviewing" with a feminist new materialist lens. By intra-acting the interview live, we aim to understand how these artists build feminist activist communities online through their political representations of gender, feminism and sexuality. We position the agency of the interview as enmeshed with the body in space and the body in digital and virtual environments. Together, we examine the politics embedded in art making and sharing processes that allow for intersectional dialogues of inclusion to emerge through the entangled differences between bodies, cultures, religions and sexualities. We align these digital understandings and art practices with the community arts workshops that foster interfaith relations and the sharing of religious differences amongst children of different faith backgrounds, including secular children (Hickey-Moody 2018; Hickey-Moody and Harrison 2018). Our theorisation of these digital and social communities are sites for comparison and we see the creative methods used to entangle ourselves within these spaces as parallel to one another. The discussion in this paper highlights how practices of blurring the boundaries between the virtual and the real in community art practice makes way for a new materiality of communities that are based on difference. We discuss our findings in relation to understanding how the communities we engage with experience diffractions of difference as an expression of 'belonging'. We look at examples of fieldwork from both projects that amplify the significance of belonging, togetherness, acceptance and inclusion as expressed through art in both religious and newly arrived communities as well as feminist digital art groups.

We write as two white women, one of us is a Canadian migrant of post WW2 Jewish and German descent and the other a first-generation daughter of two migrants from Ireland and England who moved to Australia in their mid-twenties. Our experiences of migration and negotiating diaspora offer important points of connection when becoming with our research participants in exploring themes of home and belonging. One of us is the child of an Irish political musician and IRA sympathizer, for whom the embodied history of the Irish civil war and famine have been key to learning about the politics of colonization and problematizing relationships between religion and social/cultural power. The history of the Cromwellian Penal Laws against Catholics in Ireland, which denied education,

1 Professor Anna Hickey-Moody is recipient of the Australian Research Council Future Fellowship project number FT 160100293 'Early Start Arts to Counter Radicalization' funded by the Australian Government. 
emancipation and landownership to any Irish Catholic were not repealed until 1829 and is echoed in the class system in Ireland, which is shaped by a complex enmeshment of religion and geography. The close relationships between war and religion embedded in Irish history were the inspiration for part of the fieldwork discussed here, which examines relationships between religion, community and belonging. Similarly, Holocaust histories constitute the genetic material of any Jewish survivors of WW2 and their descendants. This generational trauma and attunement to a past history of conflict is a point of connection that can often be part of becoming with our research participants from migrant backgrounds and refugee pasts. Our places of connection in relation to gender and sexuality which is further explored in the Instagram research here are similar forms of enmeshment of difference: one of us identifies as bi-sexual and as both of us present as women, we consistently experience patriarchal and capitalist overcodings of our bodies that leave us profoundly attuned to the power of queer, decolonial feminist imagery. We share crucial points of connection with our participants and consistently look to learn from and celebrate our differences as being a form of community 'togetherness'.

\section{Diffracting Difference}

Diffractions and entanglements of matter and meaning emerge from the telling, making and drawing of visual 'migration stories' in the UK and Australia (Hickey-Moody 2018), and also in the feminist activist art we see on Instagram. The depth and diversity of the communities that we study in relation to their sense of belonging, togetherness, inclusion and acceptance is diffracted but also brought into being through art practice.

Diffraction is not reflection raised to some higher power. It is not a self-referential glance back at oneself. While reflection has been used as a methodological tool by scholars relying on representationalism, there are good reasons to think that diffraction may serve as a productive model for thinking through nonrepresentationalist methodological approaches. (Barad 2007, p. 88)

Diffracting, or breaking apart a ray of light shows up its many components and indeed co-constructs these components in the process of diffraction. Diffraction makes in new ways, rather than mirrors. In her book chapter "Queer Causation and the Ethics of Mattering", Karen Barad (2008) re-works material from Meeting the Universe Halfway by applying 'diffraction' to the scientific discovery of the many light changing lenses of the brittlestar (an Ophiuroid). The brittlestar has a survival method of breaking off and losing some of its arms to distract predators. In this example, Barad positions brittlestars as being a part of this world, and this diffraction of their limbs symbolizes their entanglement with the environment. She asks,

When is a broken-off limb only a piece of the environment and when it is an offspring? At what point does the 'disconnected' limb belong to the 'environment' rather than the 'brittlestar'? Is contiguity of body parts required in the specification of a single organism? Can we trust visual delineations to define bodily boundaries? Can we trust our eyes? Connectivity does not require physical contiguity. (Spatially separate particles in an entangled state do not have separate identities, but rather are part of the same phenomena.) (Barad 2008, p. 327)

In broad terms, Barad (2008) is questioning why differences, and in this case bodily diffractions, are seen as being separated from the environment when she asks "can we trust our eyes?" (p. 327). She points to the notion that connectivity does not require contiguity, therefore, though something may appear different, this does not necessarily mean that it is. Barad opposes this focus on difference by redefining the space between the brittlestar's body and the environment, its limbs are diffracted into the environment rather than away from the body. She says "the world is an ongoing intra- active engagement, and bodies are among the differential performances of the world's dynamic intra-activity, in an endless reconfiguring of boundaries and properties, including those of spacetime" (Barad 2008, p. 326). In our research, bodies of water, matter, flesh, soil, sand and stone are reconfigured across 
spacetime in contextually specific ways. Religious differences and similarities are diffracted through art making and storytelling. Stories of migration, attachment, belonging, devotion and spiritual life are shared through words, colours, pattern, paint and pictures. Colors, symbols and feelings bring bodies together, and position them on shared earth. Feminist artists create and share art on Instagram with the political aim of advancing feminist agendas on themes such as LGBTQIA+ activism, reproductive justice, self-love and body positivity. It is through this entangled set of diffractions between various modes of story-telling, art making, digital creation and discussion that we find that intersecting themes of social inclusion evolve, through the creative methods with which we employ. By using intersectional feminist modes of social inclusion, Instagram artists build online communities from their art practice and actively participate in intersectional dialogue on their Instagram pages. Kimberle Crenshaw (1989) urges researchers to focus on this 'intersectionality' by looking at the conjoining oppressions at play across structures, systems and institutions. She problematizes some feminist theory and antiracist politics because of the "focus on the most privileged group members [which] marginalizes those who are multiply-burdened and obscures claims that cannot be understood as resulting from discrete sources of discrimination" (Crenshaw 1989, p. 140). Both the children artists and feminist activist artists diffract differences between their religions, races, ethnic backgrounds, sexualities and gender identities through their art making, either in a digital timespace or collaborative community workshop. These stories of intersectional inclusion told through art are how we explore the diffraction of differences as community making.

Using a feminist new materialist frame to activate ethico-political research in religion and gender at a community level, we theorize that the sharing of ethnic backgrounds, religious beliefs, gender identities and sexualities through art practice encourages a diffraction of difference as 'togetherness' by creating interfaith understandings and inclusion of diverse bodies and sexualities online. We use diffraction, intra-action and enmeshment in framing our understanding of this 'togetherness', and as a way of showing that these feelings rely on more-than-human assemblages, they rely on homelands, countries, wars, places of worship, practices of identification and objects of attachment.

Feminist and new materialist scholarship together, demonstrates the co-implication of bodies, subjectivities, places and histories. After van der Tuin (2008), Braidotti (2013), Barad (2007), Dolphijn and van der Tuin (2012), Barrett and Bolt (2014) and more, feminist new materialism accounts for this enmeshment of the social and the material, the virtual and real, human and non-human assemblage. For feminist new materialists, matter is agentic, ever changing, unpredictable and always becoming. Many feminist new materialist scholars (Hickey-Moody 2018; Ringrose and Renold 2016) posit perspectives and methodologies using methods we build upon here, grounded in arts-practice, intra-active interviewing, and embodied underpinnings of feminist identity and community research. It is important to note the co-implicated and relational nature of matter in new materialism. This is pedagogically significant in the respect that all bodies, not just human bodies, are endowed with agency and complexity. Barad's neologism intra-activity allows us to see this:

The notion of intra-action (in contrast to the usual "interaction," which presumes the prior existence of independent entities/relate) represents a profound conceptual shift. It is through specific agential intra-actions that the boundaries and properties of the "components" of phenomena become determinate and that particular embodied concepts become meaningful. (Barad 2003, p. 815)

Intra-activity is a concept grounded in philosophies of immanence. There is no 'beyond' the body, rather, the focus shifts to a 'between' located in, with and through the body, as enacted "material-discursive phenomena" (Barad 2003, p. 821). Bodies are therefore inseparable from discursive practices. New materialist theory (Barad 2007; van der Tuin 2015; Palmer 2016) suggests that we would not be the same selves outside the field in which we are constituted, and that through the entanglement of our research site and ourselves, we change, and the subjects of our research change as well. The process of being together re-makes us. An example is our art making workshops, featured in 
the photograph below, in which experiences of art making are entangled with the participants sharing of their backgrounds.

A philosophy of intra-action shows us that we make the data we collect, and indeed, creation is the object of the research process, rather than discovering something that is 'there' to be known. This complicates understandings of research methods and comes to show that the data which is generated and collected through fieldwork is co-created by the fieldwork assemblage. 'Data' is the residue of successful complex qualitative research processes that engage young people in collaborative making practices that call them to think together about the future, about social values and community life.

Our affective research method with Instagram live interviewing embodies the experience of being live on Instagram and being broadcast into the participants' world and online community. In Instagram live interviews, both the researcher and her interviewee sit staring at a phone screen-often necessarily positioned extremely close together, in the participant's art studio, or tattoo studio, sweating and noticing how awkward it is to stare at a screen while talking to one another. This embodied proximity, while awkward, also brings with it a relationality which is key to sharing information across the course of the interview. This online intra-action of the researcher and the participants' bodies is further explored and theorized as ethnographic observation through ethnographic fieldnotes.

Both fieldwork examples from Hickey-Moody and Willcox (2019)'s work respectively demonstrate how bodies and 'things' are not separate and shows how intra-actions are vital to how we come to know ourselves as humans and interact with our environments. Through unpacking examples from practical methods for data generation, we show the potential ways our students and research participants can be called on to relate to each other and themselves in our classrooms and interview spaces. Through diffractive and intra-active methods, we are enabled to draw upon memory, culture, religion, tradition, bodies, art and politics via methods that may be substantively different from ways people often are prompted to see themselves and relate to others in theory based learning environments or traditional research practices. As Barad (2014) reminds us, "Diffraction queers binaries and calls out for a rethinking of the notions of identity and difference" (p. 171). She continues, stating,

The key is understanding that identity is not essence, fixity or givenness, but a contingent iterative performativity, thereby reworking this alleged conflict into an understanding of difference not as an absolute boundary between object and subject, here and there, this and that, but rather as the effects of enacted cuts in a radical reworking of cause and effect. (Barad 2014, pp. 173-74)

Diffraction is a material shift that changes a given compound to something new. For us, art practice, whether in online platforms or community arts workshops, highlights the diffraction of difference through understanding and communicating 'what really matters' to people and brings new dimensions into our understandings of why no 'one' human is the same. Barad's theories of entanglement demonstrate that we only exist in relation to our environments and, more than this, they allow us to see our research methods as open-ended ways of changing environments and changing people. This presents quite a particular view of the research assemblage as an entanglement and as agentive, which marks a substantive move from traditional qualitative approaches and bears alignment with what Lather and Pierre (2013) have called 'post-qualitative' research. As they so astutely note,

entanglement makes all the categories of humanist qualitative research problematic. For example, how do we determine the 'object of our knowledge' — the 'problem' we want to study in assemblage? Can we disconnect ourselves from the mangle somehow (Self) and then carefully disconnect some other small piece of the mangle (Other) long enough to study it? What ontology has enabled us to believe the world is stable so that we can do all that individuating? And at what price? How do we think a 'research problem' in the imbrication of an agentic assemblage of diverse elements that are constantly intra-acting, never stable, never the same? (Lather and Pierre 2013, p. 630) 
Gerrard et al. (2017) have written at length about what they conceive as problems with new materialism. However, for Gerrard, Rudolph and Sriprakash, whose reading of new materialism is limited, recognizing enmeshment requires relinquishing the political, whereas Barad argues that enmeshment is the political effect and affect of research methods. Removing politics is impossible. The core of the critique Gerrard et al. (2017) attempt to develop suggests that new materialist and post qualitative research cannot be political or socially useful. As we will show by drawing from our empirical research with economically disadvantaged CALD (culturally and linguistically diverse) children and communities, and our work with queer intersectional Instagram artists, new materialist and post qualitative research can be explicitly political and can respond to issues of race, class, gender and sexuality. Further, our aim in positioning feminist new materialism as being inherently political addresses the postcolonial critique that Gerrard et al. (2017) raise, suggesting that post qualitative inquiry risks operating less as new mechanisms for generative and subversive post-humanist research and more as being a process of closure and erasure. Opposing this critique, the transformative nature of feminist new materialist methodologies in which art and research converge can be seen in the work of Stacy Alaimo et al. (2008), Kester (2004), Barrett and Bolt (2014) and Nato Thompson's (2015) writing on art and activism. Thompson (2015) focuses his research on art as a political intervention and shows how art today can and does inspire innovation and dramatic transformation through activists and empowered communities. Likewise, our work brings out the politics embedded in art making and sharing, in both Instagram based communities and religious spaces. Our research creates intra-active storytelling and activism which situates the entangled diffraction of differences as a symbol of community 'togetherness'. Such an intra-active, diffractive and enmeshed methodology can be performed through a range of methods, and here we further explore two examples introduced above.

\section{Methods}

We bring together two different empirical projects; the first on religion, community and belonging, and the second on intersectional, queer, feminist activist art online. The first method discussed here works at the community level to examine class, race, culture, religion and identity through three rounds of three concurrent arts workshops with children (nine workshops per child), undertaken in schools, mosques, churches, service centers and housing estates, with a view to fostering and understanding interfaith relationships in childhood and understanding geographies of belonging as experienced by parents. By providing art practices as a way of communicating things children find difficult to articulate, art making can often help researchers uncover what matters most in the children's worlds and create pathways for building relationships with the children's parents. Our second method works on Instagram and examines gender identity, sexuality and community through social media activism, both via an analysis of feminist activist artists' work published online and through live Instagram interviews with the artists. We present both methods here to outline two possible examples of our broader intra-active, entangled methodology of creative research practice and use intra-action as a lens to pursue an explicitly political and politicizing research agendas.

\subsection{Interfaith Childhoods: Race, Class and Community}

The global landscape surrounding the mediated politics of religion and the racialization of religion changed significantly after September 11th, 2001 and the associated mediated fear of Muslim culture in 'secular' society remains a social issue in Australia and the U.K. The enduring politicization and racialization of Muslim identities that has been brought about by the post 9/11 media landscape is, in part, what we work to problematize and change through the Interfaith Childhoods project. More than this, however, the broader media framing of religion in terms of war and terror and a paucity of curriculum treating religion in Australian public schools generates a profound lack of understanding about the vernacular significance of religion in community life. Religion often sustains people and communities in adversity, and also in everyday life. This practical and significant value that can be attributed to religion is too often omitted in media reportage. Countering exactly 
such aggressive representations of religion, our interfaith research shows how children's creative and physical geographies can communicate quite complex information about their religions and worldviews (which include Christian, Hindu, Atheist, Muslim, Catholic). Ethnographic observations of children's faith worlds can be developed while spending consolidated time with them making art and discussing worldviews (see James 2001). Thinking through transnational and trans-local mobilities that are embodied by the children and are embedded in their representations of their religion and their own re-telling of their heritage and migration stories is a critical reflexive strategy that shows up the meaning embedded in the materiality of art making (see Hickey-Moody 2018). Children's artworks depicting identity, belonging and community offer a kind of speculative future, comprised of 'what really matters', namely, containing the social values the children hold in the highest regard. As noted, the children are from a range of religious and secular backgrounds and their imaginative futures often depict religious and secular social unity. The project, then, is designed to develop new ways of listening to community perspectives on belonging, identity and religion (Figure 1). In so doing, this research shows the intra-action of place, belief and biography, race, class and community, as central to (indeed, as co-constitutive of) children's identity.

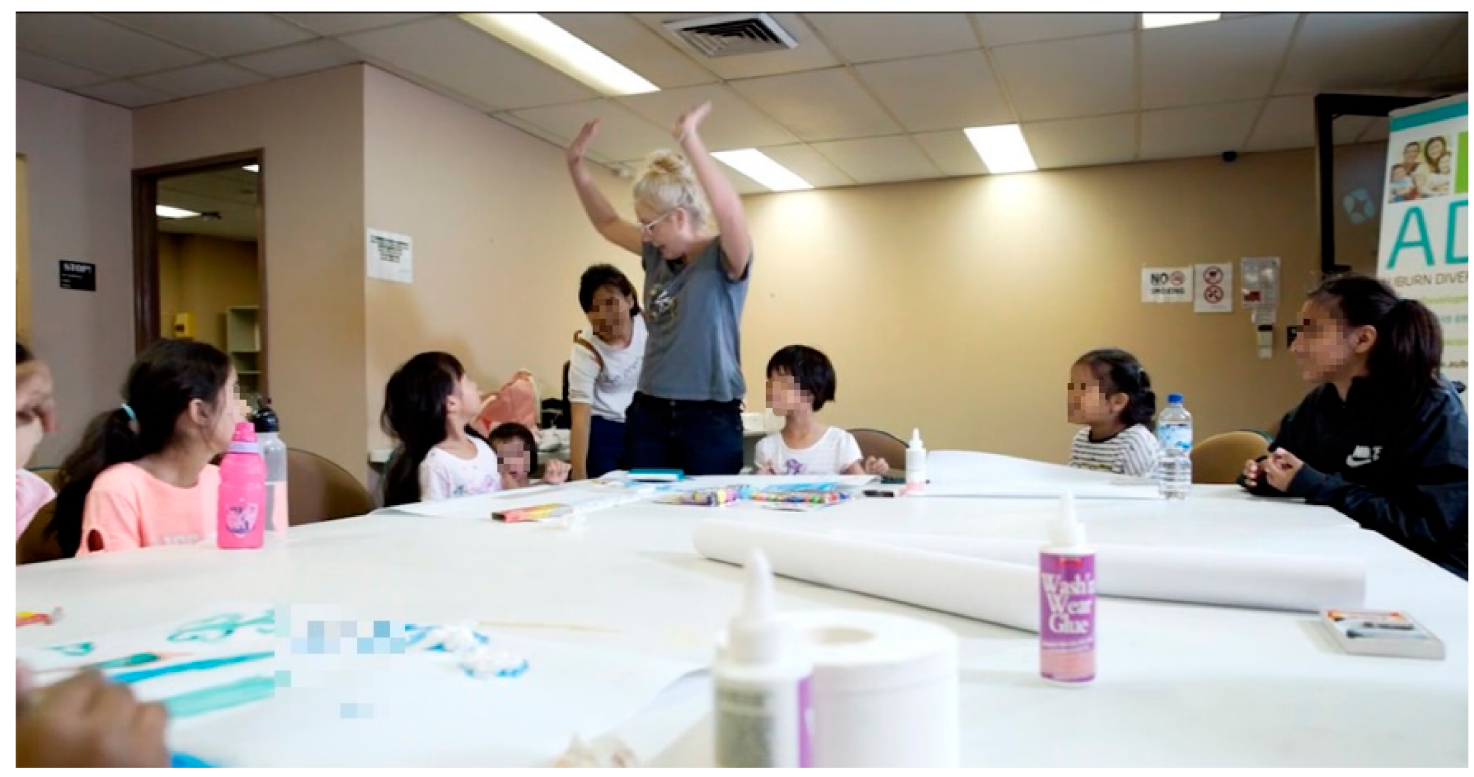

Figure 1. Making and belonging: children and researcher share stories of home. RMIT University Human Ethics Clearance Number 21071.

The methods for this project are designed to gather three sets of data and these are:

1. Visual, imaginative data collaboratively developed with children, exploring faith, values and community

2. Focus group data from the children's parents exploring faith, values, belonging and community, which is expanded upon in detailed individual interviews with parents

3. Quantitative mappings of values, beliefs and sentiments of belonging in the communities in which the qualitative data is gathered.

The analysis below is concerned with some of the visual qualitative data from children, which offers rich depictions of the material organization of religious culture and provides multiple perspectives on experiences of faith, and shows how faith is mediated creatively across digital and popular culture. Recent images of interfaith futures developed by children from England and Australia include, but are by no means limited to, the following Figures 2-4: 


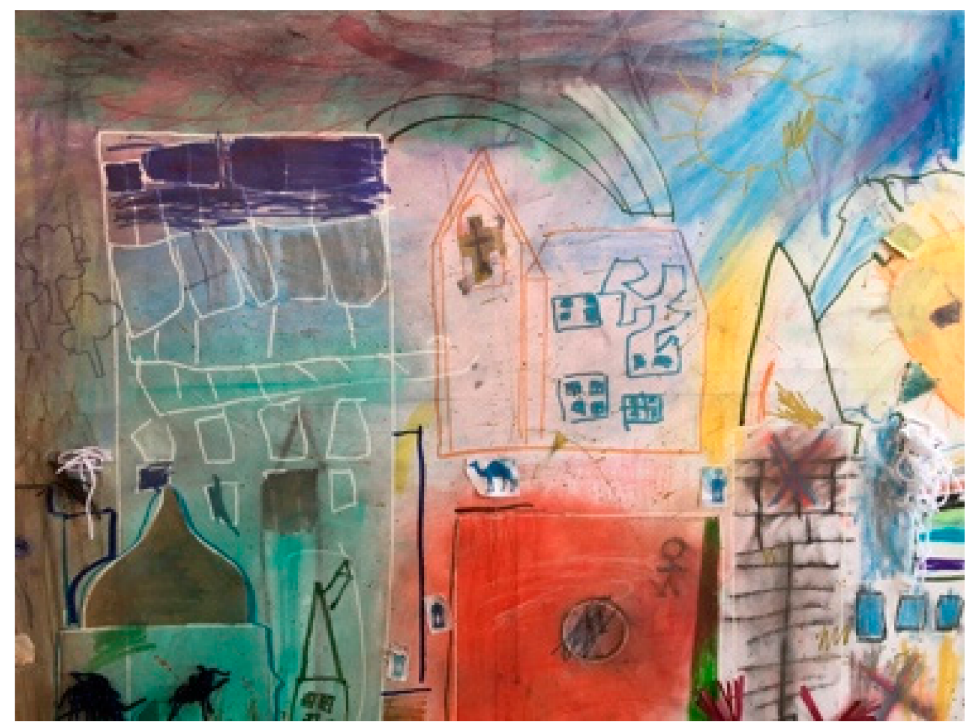

Figure 2. Future city, example one from a northern English Primary School, 2018. This image features a mosque, a church and two high-density housing estates. RMIT University Human Ethics Clearance Number 21071.

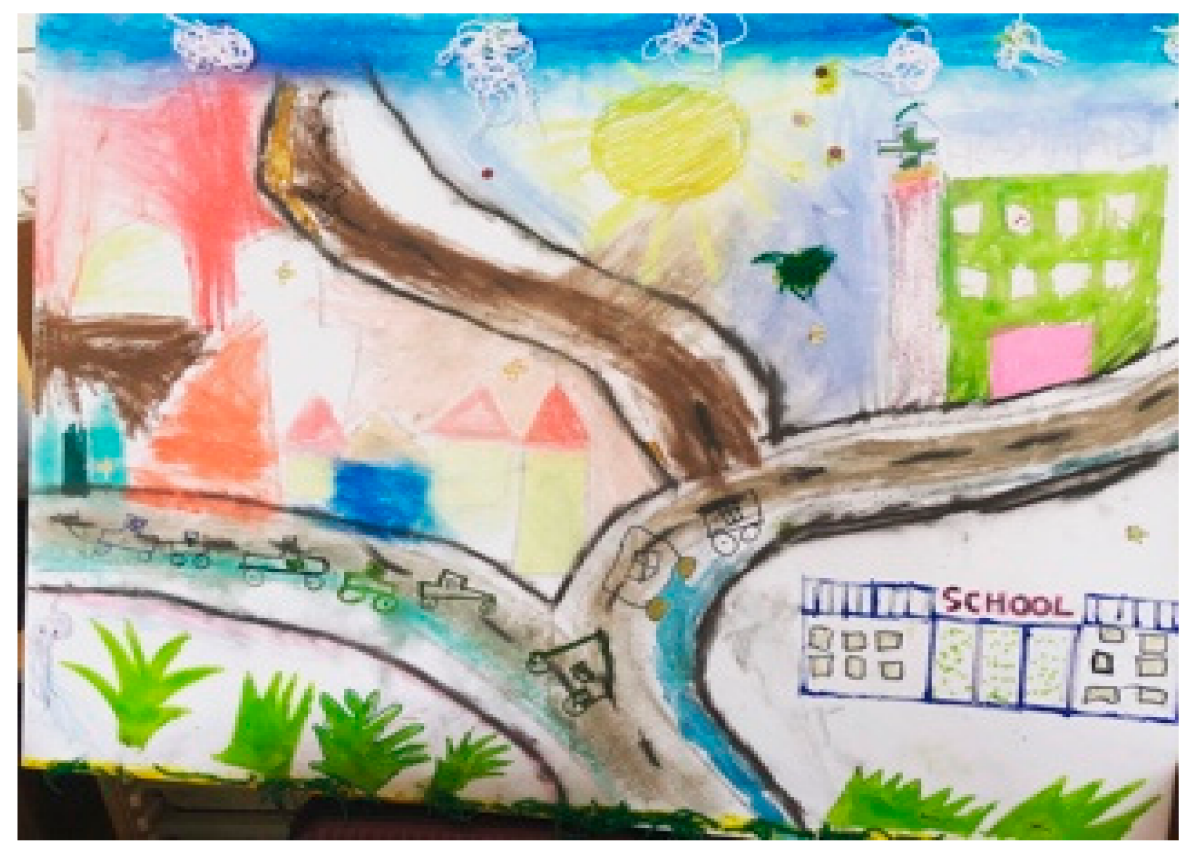

Figure 3. Future city, example two from a northern English Primary School 2018. This image features a school and a hospital (the green building) a mosque, a church and a number of houses. RMIT University Human Ethics Clearance Number 21071. 


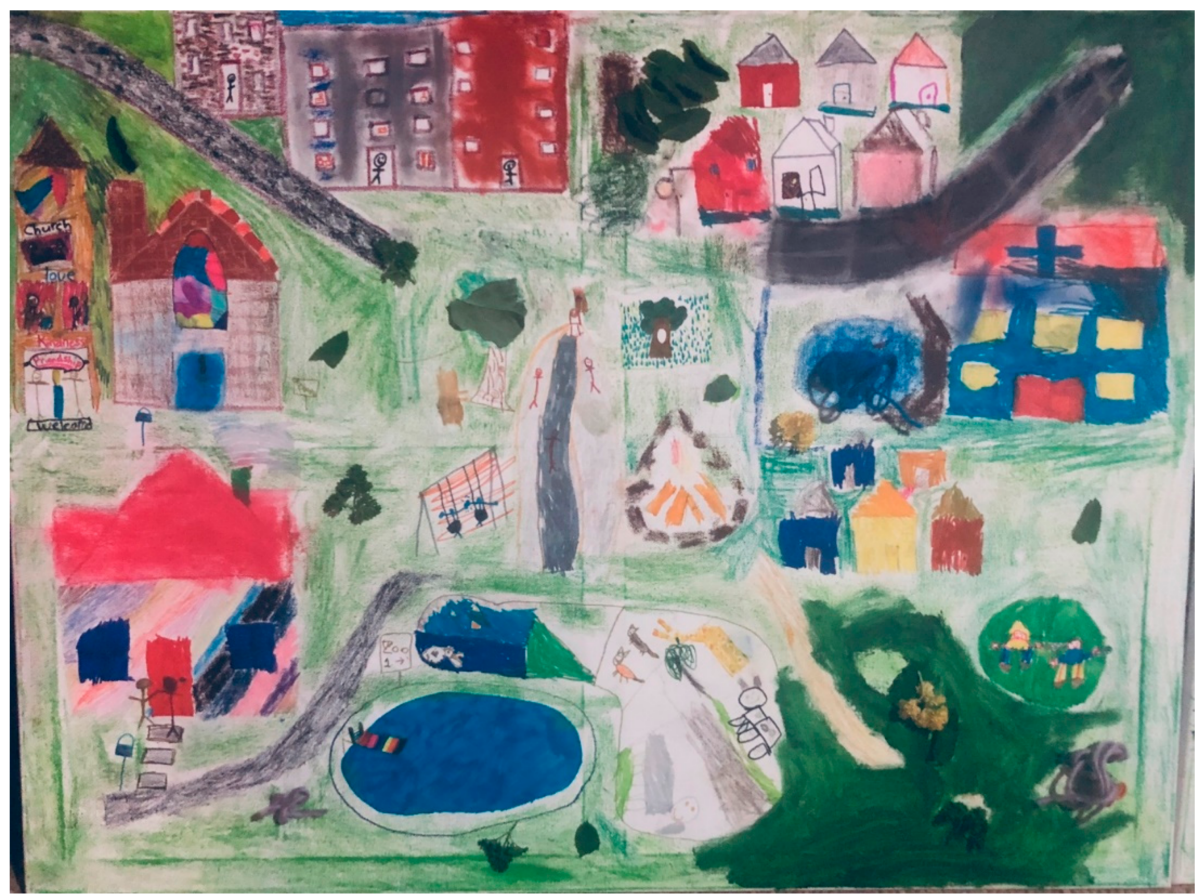

Figure 4. Future city, example from an Australian church youth group, 2018. This image features a community pool, a zoo, a campfire, a large playground, a church with stained glass windows, a hospital and number of houses. RMIT University Human Ethics Clearance Number 21071.

These three collectively devised images (Figures 2-4) are all large canvasses that have been collaboratively drawn and decorated by groups of 4-6 children aged between 4 and 9 using pastels, felt tip pens, paint pens, and collage materials (including wool, felt, cotton printed fabric). These canvasses depict imagined future cities comprised of "what really matters". Figure 2 features a mosque in the lower left-hand corner of the picture, positioned in front of a large high-rise block of flats. There is a church in the middle of the painting and further housing to the right of the canvas. At first glance, this city is clearly designed for high density living. Trees and a sun decorate the backdrop of the painting. Figure 3 features a large hospital, a mosque, a church, busy roads, houses, and a school. Strikingly, there are not a lot of people in these images, even though there are lots of places designed to be inhabited by people. Figure 4, created in Australia as opposed to the UK, bears some similarities to the UK images, although 11 people and 6 animals feature in this city, which marks a stark contrast to images from the UK, that only gesture towards people through drawings of cars.

While issues of race and class are not explicitly pictured in the works above, negotiations of issues of race and, to a lesser extent, of class, are core to the process of collaboration through which many children come to work together. More than this, negotiation of these issues is often central to these children's everyday lives. The children are from a range of predominantly non-white backgrounds and, in many instances, they are the first member of their family to have been born in the UK or Australia. With the exception of one church group, whose picture above features the swimming pools, zoo and church with stained glass, all the children in the study live and attend school in an incredibly diverse, indeed, what Steven Vertovec (2007) has called a 'superdiverse' area. Vertovec argues that superdiversity in Britain "is distinguished by a dynamic interplay of variables among an increased number of new, small and scattered, multiple-origin, transnationally connected, socio-economically differentiated and legally stratified immigrants who have arrived over the last decade" (Vertovec 2007, p. 1024). The postcode for the area in which images 2 and 3 were created is in the top $5.2 \%$ of deprived 
areas in the $\mathrm{UK}^{2}$. It is an area in Manchester, which, along with its position of economic deprivation has a substantively higher level of ethnic diversity than Manchester as a whole (UK Census 2011). It is estimated that the ward contains the third highest proportion of residents belonging to the Pakistani ethnic group ${ }^{3}$. The religious make up of this area is 32.7\% Muslim, 30.2\% Christian, 24.5\% No religion, 1.2\% Sikh, 1.0\% Hindu, 0.9\% Buddhist, 0.3\% Jewish, 0.1\% Agnostic ${ }^{4}$. As such, issues of acceptance of belief systems other than one's own are central to community life in this area.

As a result of being embedded in a superdiverse and deprived community, navigating issues of race, language, culture and religion are a required component of these children's everyday lives. Both implicitly and explicitly, these children are called to consistently respond to racialized and racializing imperatives, which can at times be advanced through social constructions of their religion. Researching with children requires the researcher to create multiple opportunities for children to communicate through indirect discourses, as often children will express themselves through doing, through the ways in which they conduct themselves and the kinds of values they perform in their expressive and representational practices. Indirect discourses are the formative materials upon which majoritarian meanings attributed to race, class and gender are built and, as such, they deserve serious attention. More than this, intervening in the configuration of discourses can be made possible through working at intersections of the discursive and non-discursive.

\subsection{Thinking with Matter}

The future cities depicted above, which were developed by the children, offer an opportunity for them to show how they might like to remake the world and to express the aspects of the world they find the most important. The values and desires represented in these images are shaped by the belief systems that surround the young people with whom we work with and these values shape their day to day lives as well as their imaginations. The children's visual and expressive artworks provide resources that inform our conversations with their parents, whose experiences (often these include experiences of migration) have been mediated and supported by their involvement in specific communities, often religious communities. Two further examples of children's expressive representations of their migration and / or religion stories can be found below.

Figure 5 features the blue color of the Somalian flag as the ozone layer surrounding the world, and a globe which depicts the child's journey from Somalia to the UK. The globe features a small car driving across it's midline, presumably taking the child and his family across the globe from one country to another. There is a clear sense of journey and the smallness of the car driving across the large globe gives a sense of the enormous nature of the journey that the young artist had undertaken. The boy had been living in the UK for two years, so the journey was not far from memory and is still very much part of his identity story.

2 A total of $94.8 \%$ of English postcodes are less deprived than M14 7JB: (it is in the top 5.2\% most deprived areas). Retrieved from: https://www.getthedata.com/postcode/M14-7JB. (GetTheData 2019)

3 Retrieved from: Whalley Range ward profile-Manchester City Council.

4 Retrieved from: Whalley Range Demographics (Manchester, England)-LocalStats. 


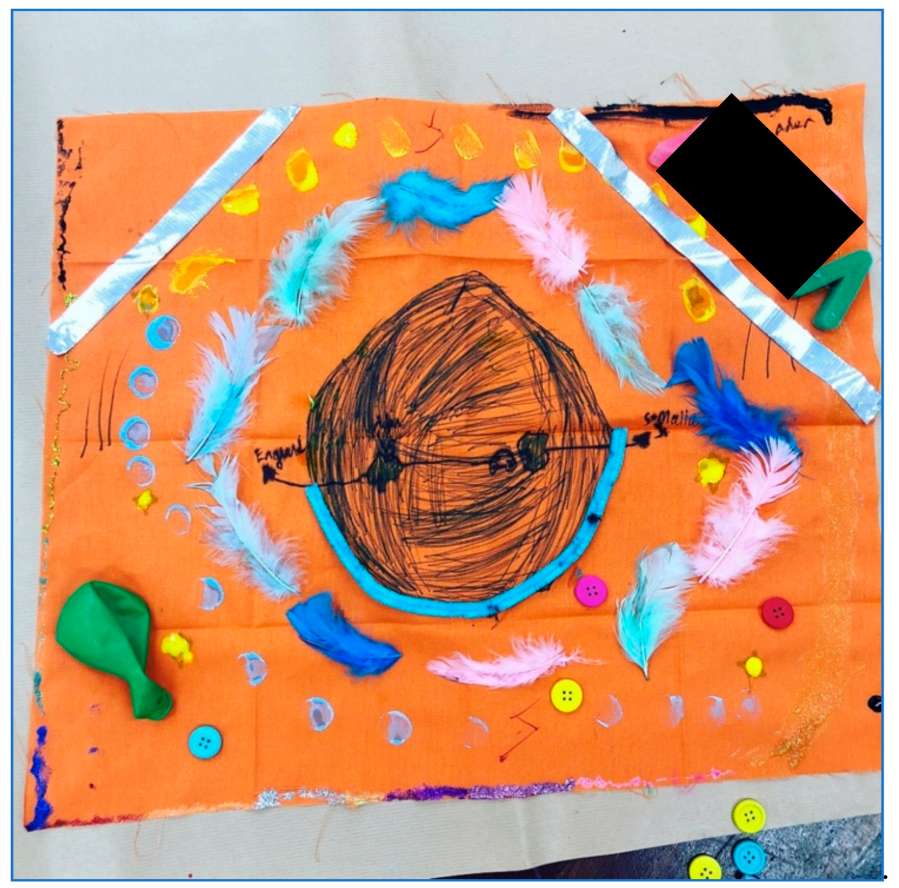

Figure 5. Expressive representation of migration from Somalia to the UK drawn by a South East London boy. RMIT University Human Ethics Clearance Number 21071.

The second picture about migration, religion and identity, which is featured below, is more symbolic and less of a literal depiction of a migration story. In addition to implied geographical movements, the image addresses themes of religion and culture, family and ritual. All these themes are very important to the artist who painted the textile work.

In Figure 6, the girl who created the picture brings together family, her religion, and popular British culture through naming celebrations such as Easter and Christmas in love hearts. Looking at the image, we can get a sense of where the author/artist feels she fits in the world, especially in relation to the other people, experiences, and events that shape her. Her artwork features shades of blue that are prominent in Islamic material and visual cultures. The family tree contextualizes the child artist amongst her family and she has included heart shaped speech bubbles as balloons that express things she thinks "really matter". These include family celebrations and cultural festivals, along with the aforementioned British national holidays of Christmas and Easter, she has listed Ramadan, Eid and 'birthdays', which are grouped together in a rhizomatic clumping of the defining celebrations in this child's life. 


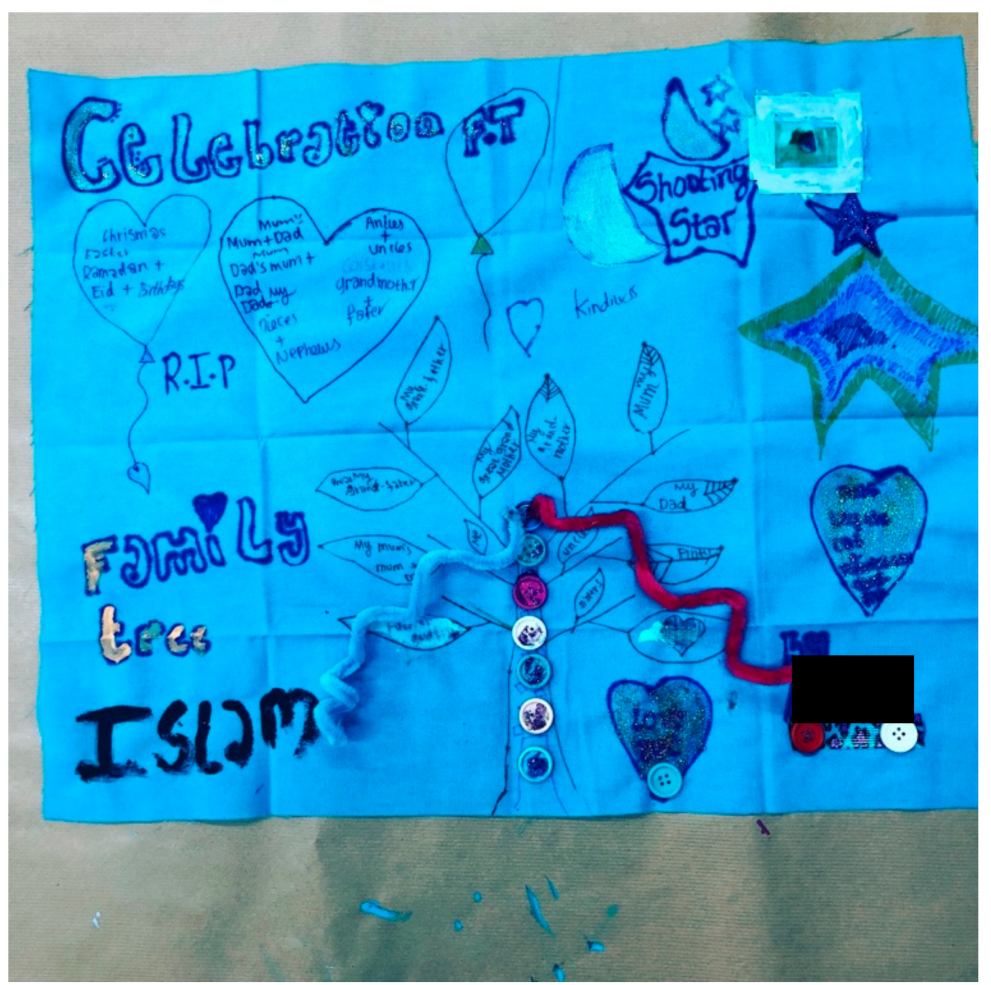

Figure 6. Expressive representation of religion, culture and belonging. Created by a South East London girl. RMIT University Human Ethics Clearance Number 21071.

These materials (Figures 5 and 6) re-present family stories, life experiences and cultural worlds. They also offer us a different comment on the material organization of culture to the existing work of scholars who consider visual and material cultures of religion. Children position belonging in relation to both Muslim and Christian/Anglo festivals and position family clearly at the center of belonging. This perspective takes seriously the pedagogical nature of materiality, building upon Karen Barad's argument that

Reality is therefore not a fixed essence. Reality is an ongoing dynamic of intra-activity. To assert that reality is made up of phenomena is not to invoke one or another form of idealism. On the contrary, phenomena are specific material configurations of the world. Phenomena are not mere human or social constructions (and they are surely not mere constructs); we don't simply make the world in our image. (Barad 2007, p. 206)

This perspective fundamentally shapes our understanding of all the subjects introduced above. Religion is not a fixed essence. Race is not a fixed essence, but it is a material agent. Religion, race, culture and society are "specific material configurations of the world" that include enmeshments of people and matter in ways that re-make meaning and attachment.

\subsection{Digital, Intra-Active Methods}

In our Instagram research ${ }^{5}$, the political issues addressed predominantly relate to gender and sexuality, while race, class, reproductive rights and religion come into focus as well. Taking a feminist new materialist approach to autoethnography, our social media research creates a narrative around the subjective experiences of identity and community making in online Instagram art. With 10 international Instagram artists from various feminist political positions, we present data from our research with 
Melbourne based Instagram artist Frances Cannon (@frances_cannon). We position this work and the methods discussed here, as a different method-expression of the same new materialist methodology performed in the Interfaith Childhoods' project. The methods demonstrate the politics embedded in art making and sharing processes, as the themes discussed in both the Interfaith Childhoods art workshops and in the Instagram research draw a transversal line joining race, religion, belonging, gender, sexuality, identity and more. What stays constant is the underlying philosophical commitment to enmeshment and to intra-active methods that show us how various differences are diffracted through art to create this 'togetherness'. Performing an Instagram live interview on the participants' Instagram page creates an intra-action of bodies (Figure 7). We blur the imaginary and real barriers that divide the digital and social worlds through this process (Hillis et al. 2015). By embodying the experience of being and performing live on Instagram, we are given a share of the participants' world and online community, and in effect, aim to minimize the much-contested qualitative researcher/subject power imbalance (Dolphijn and van der Tuin 2012). Instagram live interviews are framed here as a new materialist way of rethinking subjective experiences of identity and community making. The interview questions are tailored to fit the individual activist themes, and they change based on the participants thoughts/topics of interest during the live engagement. The conversation is broadcasted through their Instagram live story immediately, which contributes to their goal of community building through social media engagement and digital communication.

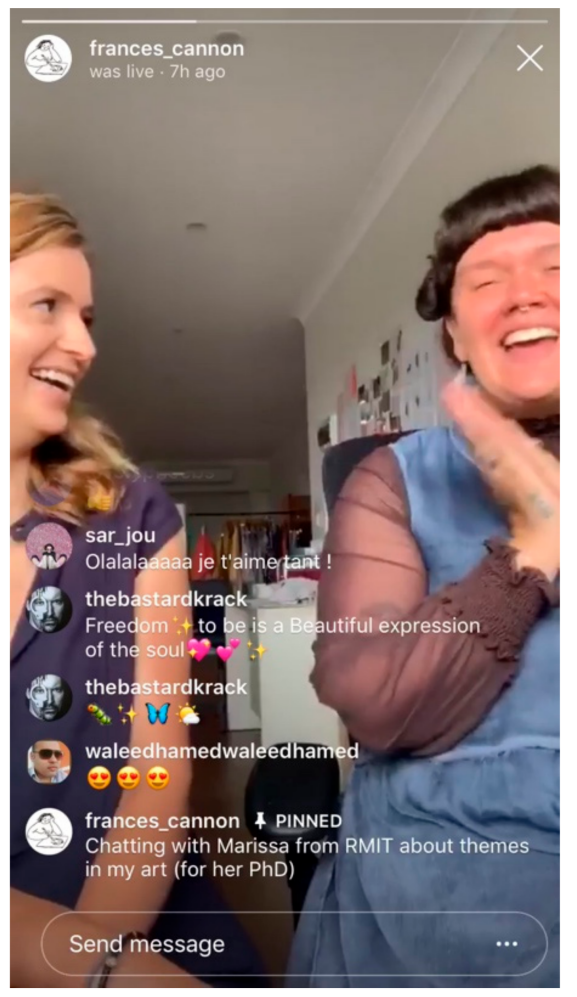

Figure 7. Intra-acting the interview. RMIT University Human Ethics Clearance Number 21229.

A live intra-active interview thus, is co-created with the participant in a way which privileges the being over knowing in researcher/participant relationships (Back 2012; Lather and Pierre 2013). We demonstrate how bodies and things are not separate, and show their inter-relationship is vital to how we come to know ourselves as humans and interact with our environments. All research participants are feminist, and most are queer-identified. Most are also same-sex attracted. Participants' art practice and their arts-based community become a site for research, and a conversational tool. The topics that participants discuss in their interviews draw them back to the themes found in the participants' 
art online. This entanglement is discussed in front of the participant's live audience: their followers and community.

Situated knowledges is not merely about knowing/seeing from somewhere (as in having a perspective), but about taking account of how the specific prosthetic embodiment of the technologically enhanced visualising apparatus matters to practices of knowing. (Barad 2008, p. 326, quoting Haraway 1997)

To put Haraway's point another way, having and gaining knowledge is therefore not a practice of seeing or reflecting from a removed position, seeing co-creates the position, it is a process that is concerned with embodying and being with/in the place of inquiry. As affective researchers, understanding only comes through doing, being, making, and feeling. Especially in interviews, "those involved in the interview come together to form an assemblage that exceeds the individuals themselves" (Willink and Shukri 2018, p. 188). Non-hegemonic gender and sexual identities and themes of online community inclusion become enmeshed with aesthetics of style through conversations with artists that explore these themes in their artwork. The method is outlined in greater detail below.

Frances Cannon's art takes on a feminist activist perspective while also illustrating pieces of her life and aspects of her own identity. Figure 8 is a reflection of the experience of being a woman on Instagram and brings up the notion that traditionally, representation of women's bodies in the media has been (and still is) 'for the male gaze'. This post (Figure 8) now has over 8000 likes and more than 100 comments. Frances initiates a dialogue around feminism, body positivity, the media, and unsafe online spaces through this transgressive art. Frances Cannon's followers are seen coming together to discuss their different experiences relating to this image in the comments section, and her art looks to unite them in their varying feminist political agendas.

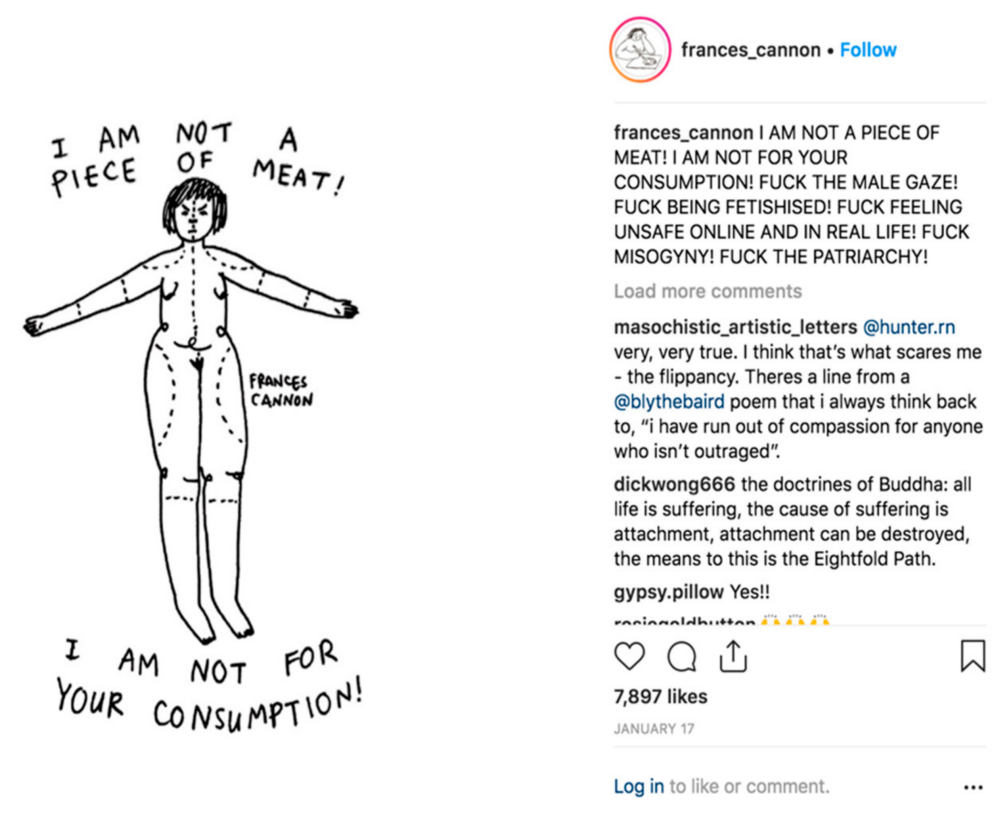

Figure 8. “I AM NOT A PIECE OF MEAT!” from @frances_cannon, Instagram, March 2019. RMIT University Human Ethics Clearance Number 21229.

Coming from a new materialist lens and working with intra-action rather than interaction, we build on Dolphijn and van der Tuin's (2012) approach to understanding interviews as outlined in New Materialism: Interviews and Cartographies. They describe how the attitude towards interviews should be seen as an intra-action, stating:

Qualitatively shifting any atomist metaphysics, intra-action conceptualizes that it is the action between (and not in-between) that matters. In other words, it is not the interviewers or 
the interviewee or even the oeuvre of the interviewee that deserves our special attention, but it is the sense of orientation that the interview gave rise to (the action itself) that should engender us. For it is in the action itself that new materialism announces itself. (Dolphijn and van der Tuin 2012, Introduction)

This approach conceives the interview process as an ongoing intra-action of bodies and places. The objective of the researcher in any new materialist methodology is to become with and be entangled in the research as it progresses. Engaging with "complexity, uncertainty and risk" as Jen Ross (2017) suggests in digital media-based pedagogy, we embrace continuous "not yet-ness" in methodological processes. Through online live interviewing, 'data' is made instantly available to the participant's global community of followers and the live nature of the interview makes every discussion unique. Planned topics for discussion can often change in response to the participant's political agenda and online persona. This intra-action is a way of making space for social change by initiating academic interest in the intersectional dialogues of inclusion that are being broadcast online, therefore encouraging and supporting communities that diffract differences.

\subsection{Creating and Mediating the Feminist Self: Live Broadcasts}

We outline the live Instagram method here, alongside an initial ethnographic observation that encapsulates the experience of entering Frances Cannon's community space, as the community surrounding Cannon's artwork is a powerful agent in supporting her work: "the virtual, therefore, can be understood as the potentialities, investments, and imaginations concerning the present and the possible shape of things to come" (Hillis et al. 2015, p. 9). The fieldnote excerpt below expresses the feelings of community and belonging that exist amongst the feminists in this digital space. Without meeting Frances Cannon's followers in person, entering her studio and entering her Instagram story show the levels of complexity in modern identities of community, time and space. We think through how these online and offline spaces for inclusion and acceptance diffract feelings of difference.

The method for this project situates the researcher in an ongoing intra-active engagement online while blurring the distinctions between the online/offline experience. Three different methods are enacted to build a feminist autoethnographic narrative based on case studies using 10 international Instagram artists:

1. An initial private semi-structured interview, exploring how feminist artists represent and express gender, sexuality, feminism and the body in art practice on Instagram.

2. A follow up interview, conducted on the participants' Instagram live that engages in a discussion around gender, feminism, sexuality and the body but with a lens to understanding the feminist activist art community and mapping the artists' engagement within that community (this is visually recorded through the engagement of their followers with the live video).

3. A continued and ongoing documentation of the artists' engagement within this global community by following their stories and posts and actively participating in this space. This is recorded through screenshots and recording the liking, commenting, and sharing of the artist's work across their various pages and stories to map community responses and sentiment.

\subsection{Ethnographic Observation: Frances Cannon's Studio, 19 February 2019}

I walked into the wrong room. Frances Cannon had invited me to her Coburg studio to conduct our second interview on Instagram live. The building had two floors. While I stood in the dark studio gallery on the bottom floor with walls covered in art depicting naked women, kissing women, breasts, blood, and the color blue, the room seemed to envelop me. I was in her space. There were other artist's paintings and drawings for sale on the walls, all with a feminist theme. I announced myself, but no one seemed to hear. I left the unlit gallery and stood outside in the hot summer air again. On the sprawling Coburg square, plots of the same brown grass stretched before me, the soil underneath them drying even more in the Australian summer heat. The 1990s style, single story, brick bungalows 
shimmered, still, as the trains blew past. Frances opened the side door to the building and waved me in. She kissed me on the cheek and showed me upstairs to a somewhat less intimate room, filled with desks and art and paper everywhere. It was an artist's haven. I quickly used the bathroom before our interview and noticed piled old art canvases on the floor, discarded (Figure 9). The counter was dusty and the air smelled of dry paint. I came out, and saw she was settled in her corner getting her iPhone tripod set up. I had the same one. Frances flowed around her desk to clear her art supplies away. Her denim dress swung as she cleared paper and canvases to the floor, she spoke about her upcoming solo art show. I said I would go. We got ready for our Instagram live interview and talked about the people that would comment, the questions and topics we might discuss. A friend of hers sat in the background, silently painting. As we turned on the live video on her Instagram story, I introduced myself to her audience of followers and prompted questions around gender, sexuality, the body and feminism, all relating to her art. Her Instagram community followed suit. The comments section on our live interview was flowing with likes and statements of support, awareness, inclusion, acceptance. When Frances spoke about her queerness others jumped in with heart emojis and signs and symbols of love. She had hundreds of people commenting as we spoke, and our conversation carried on. It felt rude not to stop the whole thing and address them, her followers. It was like we were speaking to them, for them. But we continued on with the interview. Sitting oddly close together yet looking forward at a tiny black phone screen. We were both sweating, shimmering like the brown bungalow houses lining the street outside. I was so nervous to be on a live platform, performing for her followers. What if I 'messed up'? What if I said the 'wrong thing'? We both smiled when the 'Feminists from Brazil' Instagram account commented on our chat with a 'we can do it' strong arm emoji and expressed their support for our conversation topics. Other followers from her community expressed their love for Frances's art and style. When I asked her about her artistic style in relation to her personal background, Frances said that she grew up in quite a conservative Christian household where queerness wasn't talked about. I then realized what all of her followers were doing online watching this video. It was the same thing Frances was doing by creating her art, just looking for a place and people to connect to, to feel loved and accepted, a place to belong. Instagram artists have created that space, an online community of belonging and acceptance.

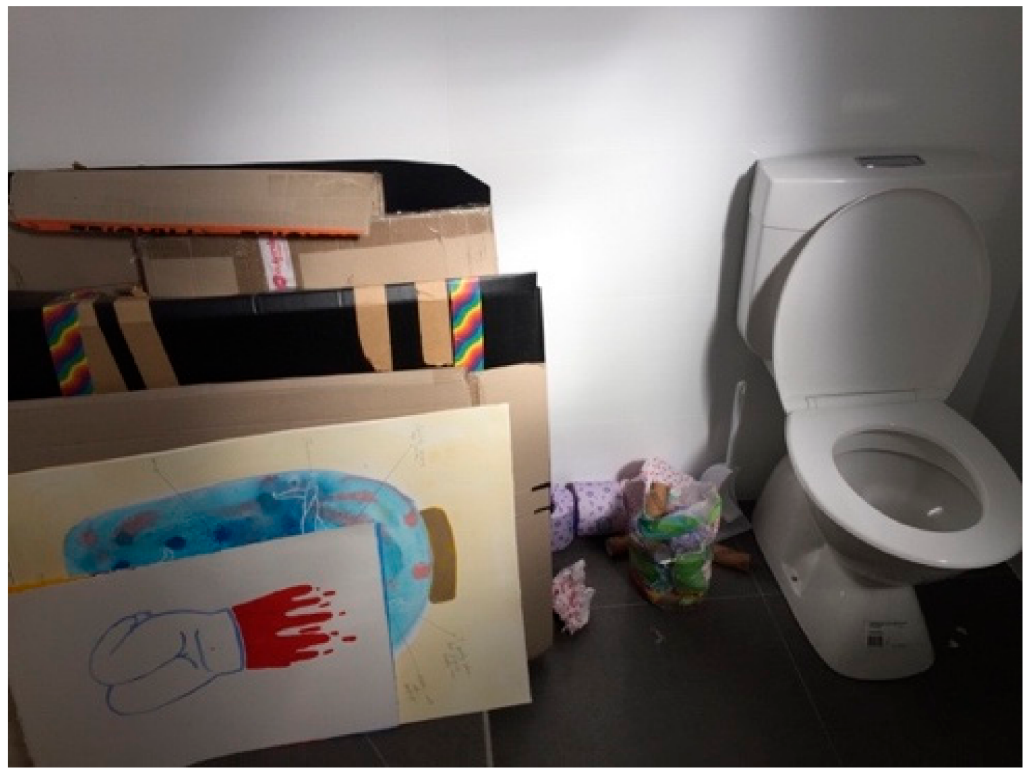

Figure 9. Discarded. Canvases on the floor in Frances's Studio. RMIT University Human Ethics Clearance Number 21229.

There was little to say when I left this online interview space, I felt like I had entered into a new world, a world of inclusion, acceptance and togetherness where feminism was at the forefront of 
everyone's minds and sexuality was a celebrated topic of discussion. We ended the Instagram live interview with advice for the future, and Frances encouraged her followers to love themselves, their whole selves. Digital heart emojis had flown across the screen for the whole 30 minutes. I packed up, hugged her and left. I stepped back into the street and noticed the square plots again, so brown, so alike, yet at the same time, still so different.

\subsection{Mixing with Matter}

Willcox's ethnographic fieldnotes from Frances Cannon's interview show the fluidity of entering into her global Instagram community while sitting (sweating) in her Coburg studio. The element of being and performing in the interview as a live action is taken as data and a mode of embodied engagement. By doing a live interview, the conversation about sexuality and body positivity is immediately translated to Frances's $186 \mathrm{~K}$ followers. The interview becomes a political and feminist statement to a live, attentive audience. Coming from the feminist new materialist frame of interviewing and understanding feminist identities in the contexts with which they are made (Colman 2014; McTague et al. 2017), we apply this concept to the new materialist trope that "every actual object is surrounded by a cloud of virtuality" (Hillis et al. 2015, p. 9). This virtuality can be seen here in the intra-active engagements between layers of love heart emojis, black phone screens, sweating bodies, followers' comments, a flowing dress, and conversations about art. When taken together, these intra-actions initiate a blurring of the boundaries between communities and identities as we see them being made. In this live discussion of Frances's politics and activist art, we can feel the diffraction of differences enabled through this digital platform as she opens up an online space for a dialogue, inclusion and acceptance (Figure 10).

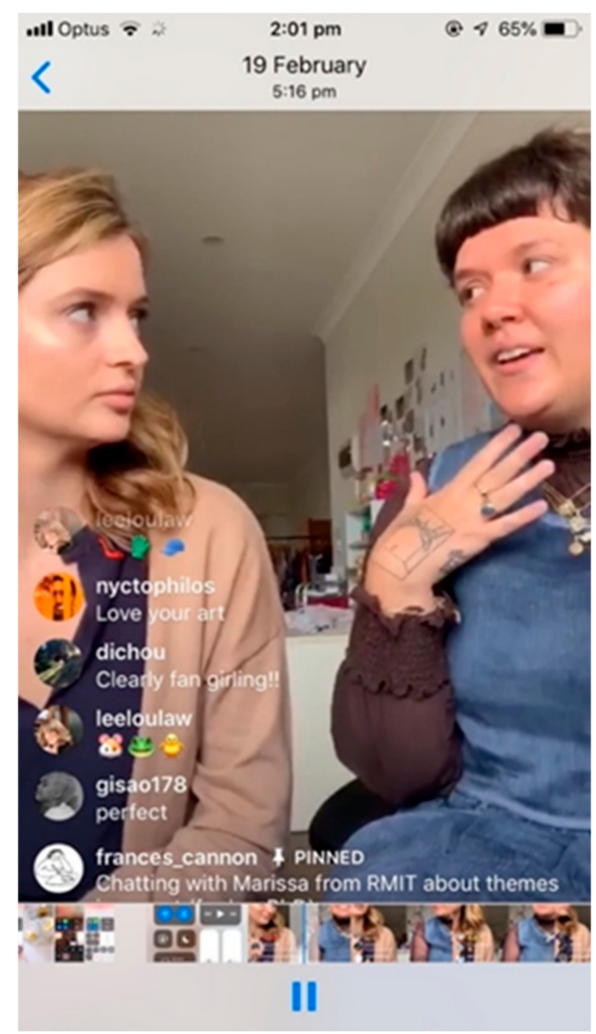

Figure 10. Digital Diffraction. RMIT University Human Ethics Clearance Number 2122.

By adopting the political position that Instagram can sometimes play a role in reproducing and reinforcing traditional gender norms and heterosexual representations (Caldeira et al. 2018, p. 23) and by intra-acting the interview in a live setting, the research aim becomes to actively change 
heteronormative, patriarchal online narratives. This method is built to amplify the experiences and identities of feminists, fat women, queer women, WOC, trans women, and non-binary artists whom often feel left out of the heteronormative online narrative, by positioning them at the centre of their identity and community making in the research process (Crenshaw 1989). It brings people of different backgrounds and experiences together over their respect for art and intersectionality, through the digital interface of Instagram. Rather than use traditional focus groups or interviews, this live style of interviewing with an aesthetic, digital, focus, offers qualitative researchers a chance to bring non-traditional representations of gender and sexuality into global online communities who share aligned interests. It serves an activist agenda by contributing a live discussion to the feminist movement online that fights for gender equality, queer inclusion and the representation of more non-white, fat, disabled and queer bodies in media spaces (Afful and Ricciardelli 2015; Robinson et al. 2019). By researching the users of these online social spaces with the same methods they use to navigate their own identities and communities, this methodology of Instagram live interviewing creates space to amplify the experiences of those who feel underrepresented in the online heteronormative narrative.

\section{Conclusions}

In both sets of the above methods, our methodology of diffractive, intra-active and entangled making with community is explored creatively. We present community focused, intra-active, arts-based research strategies for interrogating and understanding online expressions of community and belonging. With our theoretical frame inspired by entanglement, diffraction and intra-action in new materialist methodologies, we identify the fact that creative methods are a way of knowing about communities by being with communities in playful, fun and non-intrusive ways. Here, we agree with Rebecca Coleman, who states:

Drawing attention to a collective or individual sense of enjoyment may seem insignificant, but I think it's interesting for a number of reasons. For one thing, there's something to say about social science methodologies being fun and playful. This is perhaps especially important in the context of what Roger Burrows and Mike Savage (2007) call the 'coming crisis of empirical sociology', where they note that methods initially developed by sociology and wider social sciences (such as interviews, and surveys) are increasingly employed in commercial sectors-meaning both that the methodological expertise by which sociology has traditionally defined itself no longer belong to it alone, and that new audiences and markets are being enrolled in what are sometimes more agile and fun versions of these methods. So, the question of how social sciences might re-develop their own methods that are themselves fun is crucial. There is then a politics and ethics to how this question might be addressed. (Coleman 2016, online)

Our methods have to move with the times if they are to remain useful. As we argued earlier, the virtual and social worlds shown as sites for research are both understood in terms of how the potentialities and imaginaries co-constitute each other and, in turn, are responsible for the other. Each community not only diffracts their differences through art, but intra-acts with the other through an on-going time space that is concerned with the ethics of understanding and ultimately with becoming enmeshed as a community.

We have also discussed how our methodologies embody theories from the posthuman era, by doing research that thinks with the body. Rosi Braidotti (2013) outlines posthumanism in her book The Posthuman by demonstrating what it means to think within and through the body. She presents a particular kind of knowledge around difference as relating back to early humanism:

This Eurocentric paradigm [of 'Humanism'] implies the dialectics of self and other, and the binary logic of identity and otherness as respectively the motor for and the cultural logic of universal Humanism. Central to this universalistic posture and its binary logic is the notion of 'difference' as pejoration. Subjectivity is equated with consciousness, universal rationality, and 
self-regulating ethical behaviour, whereas Otherness is defined as its negative and specular counterpart. In so far as difference spells inferiority, it acquires both essentialist and lethal connotations for people who get branded as 'others'. These are the sexualized, racialized, and naturalized others, who are reduced to the less than human status of disposable bodies. We are all humans, but some of us are just more mortal than others. (Braidotti 2013, p. 3)

Braidotti's advancement of feminist post humanism and feminist new materialism are research practices that constitute a field in which we situate our research; a field which is (as the above quote demonstrates) explicitly politicized and politicizing. As we intra-act within art-based spaces, feminist activists and children express their feelings of cultural belonging, acceptance, difference, disagreement and togetherness through colour, texture, making, and doing. In community arts workshops and on Instagram, we intervene in the dissemination and re-production of problematic aspects of racializing and gendering discourses. By both intra-acting in live interviews and intra-acting in arts workshops, we learn and feel and change with the people with whom we work, as opposed to measuring and quantifying their being. We initiate a diffraction of differences in our approaches, by not privileging the knowing in research, but privileging the being with. In understanding being with as an intra-active, entangled, contextually specific experience, we aim to make new ways for people to come together and share their knowledges, experiences, and differences which help them to feel they belong or provide resources with which to negotiate difference. Understanding the collaborative production of feelings reminds us that all feelings and identities are intra-active, entangled products of communities, which we conceive as collections of difference.

Author Contributions: The authors worked on this project in conjunction with eachother forming theoretical discussions through their shared methods and methodological frames. A.H.-M. provided the first draft while M.W. expanded on the initial writing. They finalized the finished draft together.

Funding: Professor Hickey-Moody is a recipient of The Australian Research Council Future Fellowship project number FT 160100293 'Early Start Arts to Counter Radicalization' on which this project is funded. Marissa Willcox is a recipient of the RMIT RTP PhD research scholarship ID number 2266885 on which this project is funded.

Conflicts of Interest: The authors declare no conflict of interest.

\section{References}

Afful, Adwoa A., and Rose Ricciardelli. 2015. Shaping the online fat acceptance movement: Talking about body image and beauty standards. Journal of Gender Studies 24: 453-72. [CrossRef]

Alaimo, Stacy, Susan Hekman, and Susan J. Hekman. 2008. Material Feminisms. Bloomington: Indiana University Press.

Back, Les. 2012. Live sociology: Social research and its futures. The Sociological Review 60: 18-39. [CrossRef]

Barad, Karen. 2003. Posthumanist Performativity: Toward an Understanding of How Matter Comes to Matter. Signs 28: 801-31. [CrossRef]

Barad, Karen. 2007. Meeting the Universe Halfway: Quantum Physics and the Entanglement of Matter and Meaning; Durham: Duke University Press. Available online: https://www.dukeupress.edu/Meeting-the-UniverseHalfway/ (accessed on 10 June 2019).

Barad, Karen. 2008. Queer Causation and the Ethics of Mattering. In Queering the Non/Human. Edited by Noreen Giffney and Myra J. Hird. Hampshire and Burlington: Ashgate Publishing, Ltd., pp. 311-38.

Barad, Karen. 2014. Diffracting Diffraction: Cutting Together-Apart. Parallax 20: 168-87. [CrossRef]

Barrett, Estelle, and Barbara Bolt, eds. 2014. Material Inventions: Applying Creative Arts Research. London: I.B. Tauris.

Braidotti, Rosi. 2013. The Posthuman; Cambridge and Maldern: Polity Press. Available online: http://ebookcentral. proquest.com (accessed on 10 June 2019).

Caldeira, Sofia P., Sander De Ridder, and Sofie Van Bauwel. 2018. Exploring the Politics of Gender Representation on Instagram: Self-representations of Feminity. Journal of Diversity and Gender Studies 5: 23-42. [CrossRef] 
Coleman, Rebecca. 2016. Collaging workshops II: Play and Uncertainty. [Temporalrepertoires]. Available online: http://www.temporalrepertoires.org/blog/collaging-workshops-ii-play-and-uncertainty (accessed on 12 July 2019).

Colman, Felicity. 2014. Digital feminicity: Predication and measurement, materialist informatics and images. Artnodes. [CrossRef]

Crenshaw, Kimberle. 1989. Demarginalizing the Intersection of Race and Sex: A Black Feminist Critique of Antidiscrimination Doctrine, Feminist Theory and Antiracist Politics. University of Chicago Legal Forum 1: 139. Available online: https://chicagounbound.uchicago.edu/uclf/vol1989/iss1/8 (accessed on 24 June 2019).

Deleuze, Gilles, and Félix Guattari. 1994. What Is Philosophy? New York and Chichester: Columbia University Press.

Dolphijn, Rick, and Iris van der Tuin. 2012. New Materialism: Interviews \& Cartographies. London: Open Humanities Press. [CrossRef]

Gerrard, Jessica, Sophie Rudolph, and Arathi Sriprakash. 2017. The Politics of Post-Qualitative Inquiry: History and Power. Qualitative Inquiry 23: 384-94. [CrossRef]

GetTheData. 2019. M14 7JB Maps, Stats, and Open Data. Available online: https://www.getthedata.com/postcode/ M14-7JB (accessed on 1 July 2019).

Haraway, Donna J. 1997. ModestWitness@SecondMillennium.FemaleMan@-Meets_OncoMouse TM: Feminism and Technoscience. Journal of the History of Biology 30: 494-97.

Hickey-Moody, Anna. 2017. Arts Practice as Method, Urban Spaces and Intra-Active Faiths. International Journal of Inclusive Education 21: 1083-96. [CrossRef]

Hickey-Moody, Anna. 2018. New Materialism, Ethnography, and Socially Engaged Practice: Space-Time Folds and the Agency of Matter. Qualitative Inquiry. [CrossRef]

Hickey-Moody, Anna. 2019. Ways of Knowing Failure' MAI: Feminism and Visual Culture. MAI. May 15. Available online: https://maifeminism.com/three-ways-of-knowing-failure/ (accessed on 22 June 2019).

Hickey-Moody, Anna, and Mia Harrison. 2018. Socially Engaged Art and Affective Pedagogy: A Study in Inter-Faith Understanding. Tate Papers No. 29. Available online: https://www.tate.org.uk/research/ publications/tate-papers/29/socially-engaged-art-and-affective-pedagogy (accessed on 24 July 2019).

Hickey-Moody, Anna, and Marissa Willcox. 2019. Material Expressions of Religious Culture. In Religion, Hypermobility and Digital Media in Global Asia: Faith, Flows and Fellowship. Amsterdam: Amsterdam University Press, Forthcoming.

Hillis, Ken, Susanna Paasonen, and Michael Petit, eds. 2015. Networked Affect. Massachusetts: MIT Press.

James, Allison. 2001. Ethnography in the Study of Children and Childhood. In Handbook of Ethnography. Edited by Paul Atkinson, Amanda Coffey, Sara Delamont, John Lofland and Lyn Lofland. London: Routledge, pp. 246-57.

Kester, Grant H. 2004. Conversation Pieces: Community and Communication in Modern Art. Berkeley: University of California Press.

Lather, Patti, and Elizabeth A. St. Pierre. 2013. Post-Qualitative Research. International Journal of Qualitative Studies in Education 26: 629-33. [CrossRef]

McTague, Tricia, Carissa Froyum, and Barbara J. Risman. 2017. Learning about inequality from kids: Interviewing strategies for getting beneath equality rhetoric. Researching Children and Youth: Methodological Issues, Strategies, and Innovations 22: 277-301.

Palmer, Helen. 2016. Deleuze and Futurism: A Manifesto for Nonsense. London: Bloomsbury.

Ringrose, Jessica, and Emma Renold. 2016. Cows, Cabins and Tweets: Posthuman Intra-active Affect and Feminist Fire in Secondary School. In Posthuman Research Practices in Education. Edited by Carol Taylor and Christina Hughes. Abingdon: Taylor \& Francis Group, pp. 220-41. [CrossRef]

2019. The Art of Feminism: Images that Shaped the Fight for Equality; San Francisco: Chronicle Books. Available online: https://shop.tate.org.uk/the-art-of-feminism-images-that-shaped-the-fight-for-equality/22015.html (accessed on 19 July 2019).

Ross, Jen. 2017. Speculative method in digital education research. Learning, Media and Technology 42: 214-29. [CrossRef]

Thompson, Nato. 2015. Seeing Power: Art and Activism in the 21st Century. Brooklyn: Melville House Publishing. van der Tuin, Iris. 2008. Third Wave Materialism: New Feminist Epistemologies and the Generation of European Women's Studies. Ph.D. thesis, Utrecht University, Utrecht, The Netherlands. 
van der Tuin, Iris. 2015. Generational Feminism: A New Materialist Introduction to a Generative Approach. London: Rowman and Littlefield.

UK Census. 2011. QPZM Local Stats. Available online: http://whalley-range.localstats.co.uk/census-demographics/ england/north-west/manchester/whalley-range (accessed on 20 July 2019).

Vertovec, Steven. 2007. Super-diversity and its implications. Ethnic and Racial Studies 30: 1024-54. [CrossRef]

Willink, Kate G., and Salma T. Shukri. 2018. Performative interviewing: Affective attunement and reflective affective analysis in interviewing. Text and Performance Quarterly 38: 187-207. [CrossRef]

(c)

(C) 2019 by the authors. Licensee MDPI, Basel, Switzerland. This article is an open access article distributed under the terms and conditions of the Creative Commons Attribution (CC BY) license (http://creativecommons.org/licenses/by/4.0/). 